\title{
Los pliegos sueltos de romances RM686-RM685 y RM408-RM409: contextos, materialidad y ecdótica
}

\author{
Mario Garvin \\ Universität Konstanz \\ mario.garvin@uni-konstanz.de \\ https://orcid.org/oooo-o003-4312-8867 \\ Received: 03/oI/2O2I; accepted I5/O2/2O2I \\ DOI: https://doi.org/IO.7203/MCLM.8.I6884
}

The romances chap-books RM686-RM685 and RM408-RM409: contexts, materiality and ecdotics

Abstract

This article analyses four ballad chap-books (RM686-RM685 and RM408-RM409) which form two independent series of transmission, but which by their typology and context, transcend their own individuality, revealing useful information about the influence of materiality on the contents of the printed book and on the form of the poetic text, both in these particular witnesses and in later editions.

KEYWORDS

Textual criticism; analitical bibliography; ballads; chap-book

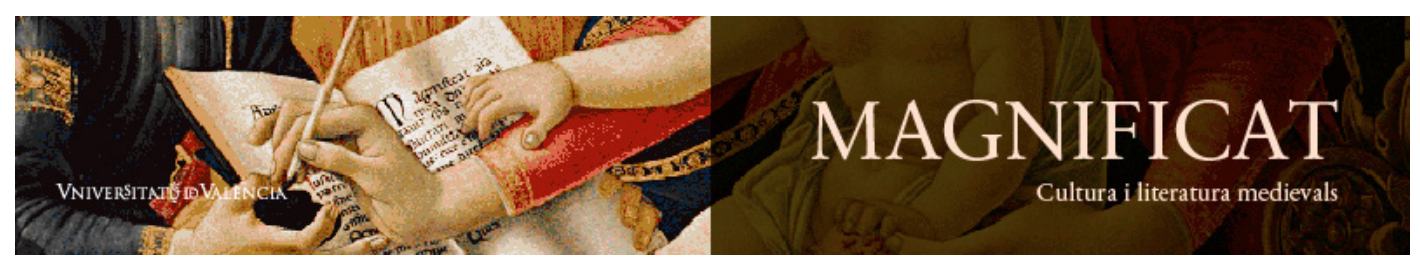

Magnificat Cultura i Literatura Medievals 8, 202I, I65-184. http://ojs.uv.es/index.php/MCLM

ISSN 2386-8295 
RESUMEN

El presente trabajo analiza cuatro pliegos poéticos (RM686-RM685 y RM408-RM409) que forman dos series independientes de transmisión, pero que por su tipología y contexto trascienden su propia individualidad, revelando informaciones útiles sobre la influencia de la materialidad en los contenidos del impreso y en la forma del texto poético, tanto en el testimonio particular como en las ediciones posteriores.

PALABRAS CLAVE

Ecdótica; bibliografía material; romancero; pliego suelto.

Mario Garvin. 202I. 'Los pliegos sueltos de romances RM686-RM685 y RM408-RM409: contextos, materialidad y ecdótica', Magnificat Cultura i Literatura Medievals, 8: I65-184, DOI: https://doi. org/IO.7203/MCLM.8.16884 (c) B

Este trabajo se enmarca en el proyecto Cancionero, Romancero y Fuentes Impresas del Ministerio de Economía, Industria y Competitividad (FFI2Or7-863r3-P), financiado por la Agencia Estatal de Investigación (AEI) y el Fondo Europeo de Desarrollo Regional (FEDER).

\section{TABLA DE CONTENIDOS}

I RM686-RM685: Materialidady ecdótica - I68

${ }_{2}$ Orígenes del modelo de RM686 - I70

3 So los más altos cipreses y una hoja suelta de Melchor de Llanes - I73

${ }_{4}$ De RM$_{4} 08$ a RM409, pasando por RM4IO - I77

${ }_{5}$ Obras citadas - I82 


\section{ə*⿻丷木}

L

a transmisión de romances en pliegos sueltos poéticos de la primera mitad del Quinientos plantea al investigador una serie de interrogantes de difícil respuesta, desde su mismo origen - ¿de dónde sacaron los textos los primeros impresores?, ¿en qué medida la forma del texto es consecuencia de ese proceso de textualización e impresión? - hasta las condiciones ideológicas y materiales de su transmisión. A pesar de que hace ya algunos años que el acercamiento otrora más bien bibliográfico a estos impresos ha dado paso a estudios más centrados en esos aspectos, existen aún muchas cuestiones que distan de estar claras. ${ }^{I}$ Y no cabe ninguna duda de que esta situación se debe fundamentalmente a las enormes pérdidas sufridas: según todo parece indicar, la tirada media para un impreso de estas características equivalía a unos I5oo pliegos, cantidad que podía imprimirse en un solo día. ${ }^{2}$ Sin embargo, reuniendo todos los ejemplares conservados y referencias indirectas, en la actualidad el número de pliegos (ejemplares) conocidos es de unos I3OO aproximadamente. Y ello teniendo en cuenta que esta cifra incluye las menciones a ediciones de pliegos que hallamos dispersas en inventarios de impresores, catálogos de libreros o bibliófilos y coleccionistas. ${ }^{3} \mathrm{Si}$ solo contásemos los ejemplares realmente conservados en bibliotecas de todo el mundo -y no me detengo aquí a cuantificar aquellos pliegos de los que tenemos más de un ejemplar, aunque son ciertamente pocos- probablemente tendríamos unos mil pliegos, solo mil... cuando una única tirada ya superaba ese número. No es de extrañar, por tanto, que Giusepe Di Stefano, uno de los mejores conocedores de este universo poético, haya caracterizado los pliegos conservados como "reliquias fortuitas de un naufragio de proporciones inimaginables" (I990: 32). A esto, además, hay que añadir que la mayoría de ese millar y algo de impresos carece de datos relativos a lugar, fecha y taller de impresión, por lo que resulta lícito plantearse qué tipo de metodología es la más adecuada a la hora de acercarse a estos impresos.

Para el caso particular de este trabajo, los pliegos sueltos poéticos que se mencionan en el título fueron escogidos buscando salvar en la medida de lo posible esos problemas, con el fin último de que los resultados obtenidos de su análisis pudieran considerarse representativos a pesar de las circunstancias arriba mencionadas. Por ello, uno de los primeros requisitos fue que los pliegos estuvieran fechados con garantías y atribuidos a un taller determinado. Como veremos, tres de los cuatro pliegos (RM686, RM685 y RM409) proceden de talleres burgaleses, siendo la imprenta de esa ciudad -para los pliegos poéticos quinientistas- la mejor estudiada de cuantas produjeron este tipo de obras. ${ }^{4}$ Por su parte, el cuarto pliego $\left(\mathrm{RM}_{4} \mathrm{O} 8\right)$ se imprimió en el taller sevillano de Jacobo Cromberger. ${ }^{5}$

I. Véase al respecto el ya clásico trabajo de Infantes (I988), así como las reflexiones sobre el contexto sociocultural en el que aparecen estos impresos que pueden encontrarse en Beltran (2005; 2005-2006).

2. Así lo recordaba Jaime Moll al afirmar que "la tirada media de un día de trabajo son mil quinientos pliegos, lo que recibe el nombre de jornada, o sea un total de tres mil golpes por cada cara del pliego, lo que representa seis mil golpes de prensa" (2003: 32).

3. Solamente gracias a las anotaciones de Hernando Colón en sus Regestrum y Abecedarium conocemos unos doscientos pliegos. Sobre los pliegos colombinos, véase Rodríguez-Moñino (ı964) y las entradas correspondientes del Nuevo diccionario. El reciente libro de Edward Wilson-Lee (2OI9) ofrece una adecuada contextualización de la figura del hijo del almirante. Dos ejemplos pertinentes de inventarios de impresores y sus pliegos pueden verse en los trabajos de Griffin (I993 y 1998).

4. Ello especialmente por la labor de Mercedes Fernández Valladares (2005 y 2006).

5. Lamentablemente, no contamos para la imprenta sevillana con un trabajo similar al que tenemos para Burgos, ya 
En segundo lugar, interesaba que los pliegos en cuestión procedieran de los talleres más representativos de la primera mitad del Quinientos o, para ser más concretos, de aquellos talleres que según nuestros conocimientos actuales - condicionados obviamente por las pérdidas notables que hemos mencionado- contribuyeron de modo más decisivo a que el pliego de romances adquiriera durante las primeras décadas del siglo la forma que se estandarizará durante el resto de la centuria. ${ }^{6}$ Finalmente, se buscaron dos pares de pliegos que tuvieran una clara interdependencia, a fin de poder dar por supuesto que esos testimonios - pese a que no podemos descartar la presencia intermedia de otros testimonios que nos son desconocidos- formaron parte sustancial de una cadena concreta de transmisión. Para los dos pares elegidos, podemos dar por seguro que en ambos casos uno de los pliegos es reedición directa o indirecta del otro. Así, de la conjunción de estos tres factores, suponíamos, podían obtenerse datos concretos que, más allá del caso particular, ofrecieran información relevante para el conjunto.

\section{RM686-RM685: Materialidad y ecdótica}

$\mathrm{E}$

l primer par de pliegos a analizar procede, como hemos dicho, de la imprenta burgalesa,

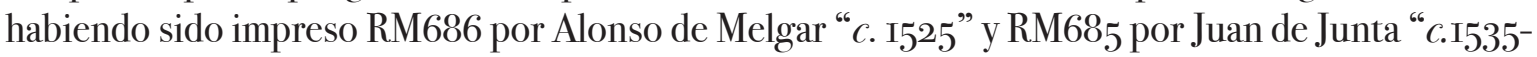

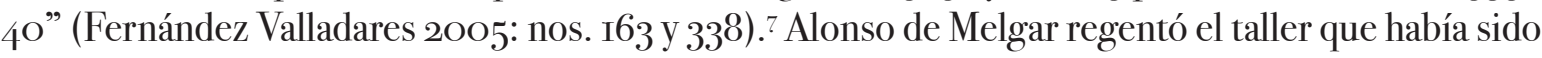
de Friedrich Biel de Basilea desde septiembre de I5I7 hasta el mismo mes de I525 y que pasaría en I527 a manos del librero de origen italiano Juan de Junta, después de que este se casara con Isabel de Melgar, la viuda de Alonso. ${ }^{8}$ No resulta por tanto extraño constatar que en el taller de Juan de Junta se reimprimieron obras que ya habían visto la luz anteriormente, durante la época de Melgar, como parece ser el presente caso. Así, basta una rápida comparación de los contenidos de ambos pliegos para constatar su -al menos aparente-igualdad:

\section{RM686}

Aqui comiençan tres romāces glosados y este primero dize Desamada siempre seas. Y otro a la Bella malmaridada. Y otro Caminādo por mis males con vn Villancico. Y vn romance.

que la obra póstuma de Arcadio Castillejo (20I9), pese a su gran utilidad para otros aspectos de la imprenta hispalense quinientista, no aporta datos nuevos sobre los pliegos poéticos impresos en esa ciudad. Para el taller de los Cromberger, sin embargo, contamos con el excelente y aún muy válido estudio de Clive Griffin (I99I), a la espera de las novedades sobre este impresor y sus pliegos poéticos que pueda aportar el estudio que abrirá la edición facsimilar de los pliegos en bibliotecas de Francia que preparan Mercedes Fernández Valladares, Laura Puerto y Joan Mahiques (en prensa).

6. Norton y Wilson caracterizaron en un temprano trabajo la presentación estandarizada del pliego poético quinientista en base a "its quarto format, the restriction of its text to a single folded sheet, its title embellished by an irrelevant reused woodcut with the text beginning immediately below in two columns, its gothic types, and its lack of any indication of place, printer or date" (I969: 5). Pese a los muchos pliegos que divergen, sea en el formato, el número de hojas u otro aspecto de esta materialidad, lo cierto es que los numerosos descubrimientos de pliegos acaecidos en los cincuenta años que median entre el trabajo de los investigadores ingleses y la actualidad, registrados en el Nuevo diccionario de pliegos sueltos poéticos (Askins-Infantes 1997) y actualizados en el Suplemento (Askins-Infantes 2OI4) confirman esa tendencia. La numeración de los pliegos remite a estas dos últimas obras. Se acompañan, como es común, de las siglas RM por Antonio Rodríguez-Moñino dejando clara esa remisión, si bien en los citados repertorios carecen de ellas.

7. Dado que el Nuevo diccionario sigue los criterios de ordenación del Diccionario original (Rodríguez-Moñino I970) la numeración de estos impresos frecuentemente no coincide con su cronología real, de ahí que tanto en el título como en los epígrafes se haya optado por citar los pliegos en el orden que corresponde a su aparición temporal.

8. Para todo lo relativo a este taller, remito a la obra de Fernández Valladares (2005: I46-I65) y a la bibliografía allí citada. 
TEXTOS:

Pensé que por bien amarte (Glosa de melchior de llanes: Desamada siempre seas) (I)

Perdonad bien de mi vida (Dessecha suya) (2)

Cuando amor que en mí ponía (Glosa de Quesada. sobre el romance dela bella malmaridada) (3)

Viendo que mi pensamiento (Glosa sobre el Romāce que dize. Caminando por mis males) (4)

Dama cogida en tu ato [sic.] (Villancico) (5)

So los más altos cipreses (Romance) (6)

\section{RM685}

Aqui comiençan tres Romances glosados y este primero dize Desamada siempre seas. Y otro a la Bella malmaridada. Y otro Caminando por mis males con vn Villancico. Y vn romance.

TEXTOS:

Pensé que por bien amarte (Glosa de Melchior de llanes: Desamada siempre seas) (I)

Perdonad bien de mi vida (Dessecha suya) (2)

Cuando amor que en mí ponía (Glosa de Quesada. Sobre el Romāce dela bella malmaridada) (3) Viendo que mi pensamiento (Glosa sobre el Romance que dize. Caminando por mis males) (4)

Dama cogida en tu ato [sic] (Villancico)

So los más altos cipreses (Romance) (6)

Como puede verse, ambos pliegos tienen exactamente el mismo título, con variantes ortotipográficas mínimas - romāces (RM686), Romances (RM685); Caminādo (RM686) Caminando (RM685) - y las mismas composiciones en el mismo orden y con los mismos titulillos, también aquí con variantes mínimas. Materialmente, se trata en ambos casos de dos pliegos en cuarto, de cuatro hojas, que exteriormente difieren solo en el grabado que los decora. ${ }^{9}$ En el caso de RM686 se trata de un grabado que según Fernández Valladares "representa a una doncella muerta, al pie de una torre, en presencia de sus padres" (2005: 376) y que en el Nuevo diccionario -al igual que en el Diccionario original- aparece descrito de forma más somera como "muerte de Melibea", no sin razón, pues procede, como también indica la propia Fernández Valladares, del "acto I6 ${ }^{\circ}$ de la Celestina" (2005: 376). ${ }^{\text {г }}$ En RM685, el grabado procede también de la Celestina, pero en este caso del onceno acto. Ignoramos a qué motivos se debió el cambio, si fue consciente u obligado por condicionamientos materiales del taller que hoy se nos escapan. El grabado del primer acto podemos documentarlo en otros doce impresos, siendo con mucho el más reutilizado. Le sigue en frecuencia el grabado del duodécimo acto, con siete apariciones. Solamente tienen una aparición el del séptimo acto ( $\left.\mathrm{RM}_{7} 66\right)$, el del octavo (RMioo5), decimocuarto ( $\mathrm{RM}_{5} \mathrm{O6}$ ),

9. En ambos casos hay edicion facsímil. Para RM686, la edición de los pliegos de Praga prologada por Menéndez Pidal (I96r: 2, 63), así como la excelente digitalización hecha por la Národní knihovna České republiky, disponible en <https://go.uv.es/TiGW6cg> [accesed Io.3.2020].

Io. La Celestina es, obviamente, la impresa por Biel de Basilea en I499-I5OI (Fernández Valladares 2005: ${ }^{\circ}$ 4). Por otra parte, me parece bastante discutible el modo en que tradicionalmente vienen describiéndose este tipo de grabados. El Diccionario de Rodríguez-Moñino es, en este sentido -y sin desmerecer en absoluto la titánica tarea de don Antonioun cúmulo de contradicciones, siendo frecuentes los casos en los que un mismo grabado se describe de manera distinta según la entrada, usando para ello conceptos notablemente arbitrarios, como puedan ser "galán”, "dama”, "caballero”, etc. Aunque mucho más precisa y con indicación de la fuente, la apostilla de Fernández Valladares al indicar que la doncella está “muerta” y que además está “en presencia de sus padres” constituye un acto interpretativo que no estoy seguro podamos llevar a cabo sin más. El uso reiterado de un mismo taco para decorar pliegos -y aun otras obras- de contenido muy distinto habla a las claras en favor de una polisemia del grabado que raramente estamos en condiciones de recuperar en su uso concreto. Es por ello que sería deseable, creo, una tipologización de estos grabados que permitiera -al igual que se hace, por ejemplo, con los tipos usados en un impreso- fijar con una sigla o una cifra de registro qué grabado exactamente está usando un impreso. Por lo demás, sobre el uso de estas estampas celestinescas en pliegos burgaleses, es imprescindible el trabajo de Fernández Valladares (2OI2).

Magnificat CLM 8, 202I, I65-I84. ISSN 2386-8295 
decimoquinto (RMioo7) y decimosexto acto (nuestro RM686), mientras que el grabado de RM685, correspondiente al undécimo acto, se documenta también en RMi77, unos Disparates de Juan del Encina impresos igualmente por Junta c.I53O, (Fernández Valladares 2005: nº 232 y 2OI2: I25), lo que acaso pudiera hablar en favor de que el cambio de grabado se debió a algún tipo de condicionamiento material, pero no lo sabemos. " Al parecer Junta prefirió, tal vez por el mayor número de posibilidades combinatorias que permitía, un juego de figuritas.

Hablar de las tipografías empleadas resulta algo más sencillo, ya que es un aspecto mejor estudiado que los grabados. RM686 presenta tipos de dos fundiciones distintas, "M2 c.I6o G ( $\mathrm{I}^{\mathrm{a}}$ línea del título y encabez. interiores)” y "M6 (b) c.97 G (resto del título y texto)" (Fernández Valladares 2005: 343-44; 576), mientras que en RM685 se emplean MA c.I48 G en el título y los títulos interiores y M6 (b) $98 \mathrm{G}$ en el cuerpo de texto (Fernández Valladares 2005: 796). La leve diferencia de tamaño en los tipos empleados para los títulos no redunda en la distribución del texto, la cual -habida cuenta que ambos grabados tienen un mismo tamaño de $5^{6-58}$ x $96-99$ milímetros ${ }^{12}-$ es idéntica en ambos impresos.

Salvando por tanto las mínimas variantes ortotipográficas, el grabado, y la diferencia en los tipos titulares, podríamos decir que ambos impresos son esencialmente iguales. Lo que no sabemos ni podemos afirmar con seguridad es que RM685 sea una reedición directa de RM686: media entre ambos impresos un mínimo de diez años, y no es en absoluto descartable que la imprenta de Junta -en el caso de Melgar parece más improbable, dado que murió en el mismo año de publicación del pliego RM686- publicara una o varias ediciones intermedias del pliego en cuestión. Tampoco una comparación de los textos arroja demasiada luz sobre este aspecto, pues las variantes que encontramos son meras erratas o variantes ortográficas. En la primera composición, por ejemplo, Pense que por bien amarte, encontramos solamente las siguientes:

v. I8. piedad no halles RM686 piadad no hallesRM685

v. 49. por muy orrible RM686 por muy horrible RM685

v. 54. lago y fondura RM686 lago y hondura RM685

v. 68. salga dentre escobos RM686 salga dentro escobos RM685

Con estos datos, pues, no se puede avanzar demasiado en esa dirección -aunque al hablar del siguiente par de pliegos veremos que algún paso más sí es posible dar-; de modo que, por el momento, me centraré en encontrar los posibles orígenes del cuaderno-modelo original.

\section{${ }_{2}$ Orígenes del modelo de RM686}

A hablar de un modelo para RM686 y de sus orígenes, damos por supuesto que RM686 no puede ser la primera edición. Si leemos de nuevo el título, veremos que hay una diferencia entre los textos que se anuncian y lo que realmente ofrece el cuaderno. Así, el título dice: "Aqui comiençan tres romāces glosados y este primero dize Desamada siempre seas. Y otro a la Bella malmaridada. Y otro

II. En la descripción de la edición de I499-I5OI de la Celestina burgalesa, Fernández Valladares indica que además de en el pliego citado, el grabado en cuestión “aparece posteriormente reutilizado en los n. 238 y 338” (2005: 355), dato erróneo, pues la entrada 238 corresponde al pliego $\mathrm{RM}_{534}$, que no lleva ningún grabado. La descripción del impreso (Fernández Valladares 2005: 668) es correcta. La distribución de los grabados de la Celestina en otros impresos puede verse en Fernández Valladares (2OI2: I24-I25), con reproducciones fotográficas.

I2. Tomo los datos de la descripción bibliográfica de Fernández Valladares (2005: 355). 
Caminādo por mis males con vn Villancico. Y vn romance.”, pero ninguno de los tres primeros romances aparece sino en la glosa. Además, resulta sospechoso que al final se añada ese “y un romance" cuando lo más normal -si se tratara de una primera edición- hubiera sido obviamente titular el pliego "aqui comienzan cuatro romances", quizá incluso con un oportuno "con sus glosas y sin ellas". En su forma, sin embargo, todo nos hace pensar que Melgar se sirve de otro u otros pliegos.

A diferencia de lo que sucede con nuestros dos pliegos estudiados, no hallamos entre los anteriores a RM686 ninguno que contenga las mismas composiciones y del que pudiera considerarse reimpresión el pliego de Melgar. Pero si rastreamos la presencia de los textos poéticos de RM686 en otros impresos, creo que es posible postular el modo en que se compuso este pliego. Las presencias de los textos de RM686 -y por tanto de RM685- en otros pliegos poéticos son las siguientes:

textos:

Pensé que por bien amarte: $\mathrm{RM}_{32}, \mathrm{RM}_{322}, \mathrm{RM}_{32}, \mathrm{RM}_{324 \cdot 5}$.

Perdonad bien de mivida: $\mathrm{RM}_{32}, \mathrm{RM}_{324} 5$.

Cuando amor que en mí ponía: RM688, RM689.

Viendo que mi pensamiento: RM688, RM689.

Dama cogida en tu ato: RM689.

So los más altos cipreses: RM352, RM412, $\mathrm{RM}_{594}, \mathrm{RM}_{384}$.

Lo primero que llama la atención es que las composiciones se dividen en tres grupos más o menos claros. El último romance, So los más altos cipreses, parece ir por cuenta propia, lo que reforzaría la idea que acabamos de mencionar de añadido a un cuerpo anterior. Los otros dos grupos son: uno formado por las dos primeras composiciones, y otro formado por RM689 (tres) y RM688 (dos composiciones). Comencemos nuestra búsqueda por este último bloque.

Tanto RM689 como RM688 son pliegos sueltos impresos en Sevilla, por Jacobo Cromberger, $c$. I520 el primero, ${ }^{13} \mathrm{y}$ en el taller crombergeriano, en I528 o más tarde, el segundo (Griffin I99I: $\mathrm{n}^{\circ}$ 299). Son varios los aspectos de interés que presentan estos dos pliegos para comprender cómo se formó RM686. Veamos en primer lugar los títulos y contenido de los pliegos.

RM689 ${ }^{\mathrm{I}_{4}}$

Aqui comiençan iij. Romances glosados. Y este primero dize. Catiuaron me los moros. y otro a la bella mal maridada. y otro. Caminando por mis males. Con vn Villancico.

TEXTOS:

En mijuventud pasada (Glosa de: Mi padre era de Aragón) (I)

Pues el consejo del padre (Villancico) (2)

La bella malmaridada (Glosado en: Cuando amor en míponía) (3)

Cuando amor en mí ponía (Glosa de: La bella malmaridada) (4)

Viendo que mi pensamiento (Glosa de: Caminando por mis males) (5)

Dama cogida en tu hato [sic] (Villancico) (6)

I3. Tomo la propuesta de datación de Norton (1978: n.949), Griffin (I99I: nº 22I) y Martín Abad (200I: nº I374).

I4. El pliego se conserva en la Bibliothèque Nationale de Paris. No hay edición facsímil, aunque está en preparación (Fernández Valladares et.al. en prensa) 
RM688 ${ }^{15}$

Aqui comiençan iij. Romances glosados. Y este primero dize. Catiuaron me los moros. Y otro La bella mal maridada. Y otro: Caminando por mis males. Con vn villancico.

TEXTOS:

En mi juventud pasada (Glosa de: Mipadre era de Aragón) (I)

Pues el consejo del padre (Villancico) (2)

Cuando amor en mí ponía (Glosa de: La bella malmaridada) (3)

Viendo que mi pensamiento (Glosa de: Caminando por mis males) (4)

Al igual que sucedía con nuestros RM686 y RM685, es muy probable que en el caso de RM688 se trate de una reedición de RM689, aunque como podemos ver, en esta ocasión los textos de uno y otro pliego no son idénticos, sino que se han producido ciertos cambios. Así, han desaparecido el romance de La bella malmaridada y el villancico Dama cogida en tu hato. Estos cambios tienen según creo razones materiales. RM689 utiliza, según Griffin (I99I: n. 22I) los tipos 2(c), 8 y I3, mientras que en RM688 se usan 2(d) y 8(a). Puesto que el tipo I3 es una letra más pequeña que los otros dos (82-84 milímetros), ${ }^{16}$ permite que quepa más texto, mientras que en RM688 habría que prescindir de ciertas composiciones. Pero hay más. Fijémonos -algo hemos dicho al comentar los títulos de RM686- en que el título de RM689 es "Aqui comiençan iij. Romances glosados. Y este primero dize. Catiuaron me los moros. y otro a la bella mal maridada. y otro. Caminando por mis males. Con vn Villancico". Dos puntos son relevantes. En primer lugar, tipológicamente el comienzo es igual que en nuestro RM686. En segundo lugar, este pliego parece confirmar la sospecha que expresábamos más arriba de que este tipo de pliegos en un primer estadio deberían contener el número de romances que prometen en el título. RM689 es suficientemente explícito, pues nos informa de que "este primero dize: Catiuaronme los moros", pero en realidad el primer texto que encontramos es la glosa a ese romance. Sí aparece en cambio La bella malmaridada, que luego posteriormente desaparecerá en RM688. Lo más lógico, por tanto, sería que en un primer momento hubiera habido un pliego que contenía los tres romances prometidos más sus respectivas glosas. Sustenta esta hipótesis no solamente lo que sucede en RM688 -y por extensión, en nuestro par RM686-RM685-, sino también en el pliego RM69o. Este pliego es también de taller de los Cromberger y fue impreso en I5I6 o más tarde (Griffin I99I: ${ }^{\circ}$ I68). El título sigue la misma tipología que los anteriores (otro indicio más): “Aqui comiençan iij. Romances glosados: y este primero dize. Estase la gentil dama. y otro de Olorosa clauellina. y otro de Bodas se hazen en Francia”. Sin embargo, el segundo y tercer romance aparecen sin glosar, mientras que la primera composición del cuaderno es Los campos llenos de flores, o sea, la glosa de Estase la gentil dama.

Hay acuerdo entre los investigadores en considerar que Jacobo Cromberger fue el primer impresor que "empezó un capítulo enteramente nuevo casi contemporáneamente a la edición de Hernando del Castillo [del Cancionero general de I5II]: la publicación entre I5II y I5I5 [...] de un manojo de romances en otros tantos pliegos sueltos" (Beltran 20i6: 79). ${ }^{17}$ Creo que de esos primeros años debería ser ese protopliego perdido en que se contendrían estos tres romances y sus respectivas glosas.

Algún interrogante más plantea la mención en el título de "Y un villancico", más aún cuando en RM689 -en RM688 Dama cogida en tu hato se ha eliminado por razones de espacio- el pliego

I5. Es un pliego en 40 de cuatro hojas. Edición facsímil en Menéndez Pidal (I96r: 2, 58).

I6. “Jacobo Cromberger lo incorporó a sus tipos en I5I2 cuando reemplazó al tipo І2; se convirtió en un tipo de texto para libros en cuarto y en octavo desde esa fecha hasta la desaparición de la imprenta” Griffin (I991: 285).

I7. Sobre la posición preeminente de este impresor en los primeros años de la imprenta peninsular y en especial en Sevilla, véase Garvin (20I9: 235-252) 
contiene dos villancicos. Según hemos visto ya arriba -y de hecho, es procedimiento conocido entre los impresores- ese villancico sería un texto añadido. Nada impide pensar que pudiera estar previsto desde el principio, es decir, que en ese estadio original el pliego ya lo llevara, pero también puede pensarse en un añadido posterior. En cualquier caso, en RM689 hay como hemos dicho dos villancicos, por lo que uno de ellos fue seguro añadido sin mencionarlo en el título. Si nos fijamos ahora en el número de versos de estos villancicos, veremos que coinciden con el número de versos de los dos romances que se pierden en el curso de la transmisión. Así, Mi padre era de Ronda tiene 34 versos, y el villancico Pues el consejo del padre, 3i; en el caso de Caminando por mis males el número de versos es exactamente el mismo que Dama cogida en tu hato: 24. Hay que tener en cuenta, además, que si se elimina una composición, en este caso un romance, lo más frecuente es que el título del romance pase a mencionarse en la glosa. Ocurre por ejemplo entre RM689 y RM688. Si el primero titula "Romance de la bella malmaridada" y, a continuación, "Glosa de quesada", en RM688, que prescinde del romance, el título se ha convertido en "Romance de la bella malmaridada glosado", algo que puede explicar, junto con el cambio de tipos, este tipo de oscilaciones.

Resumiendo, creo que probablemente RM689 y RM688 sean restos de una cadena de pliegos en la que podemos suponer los siguientes estadios. En primer lugar, un pliego primitivo, de esos primeros años de Cromberger, con los tres romances y sus glosas. En segundo lugar -esto puede ser un único paso o dos distintos- la sustitución paulatina de los romances, dejando solamente la glosa y ocupando el espacio tipográfico restante con esos villancicos. En tercer lugar, nuestro RM689: un pliego en el que aún queda el romance de La bella malmaridada sin glosa y con ella, pero que revela una constitución tipográfica particular: es, nótese, uno de los poquísimos pliegos en los que encontramos un taco interior, en el folio 3v. El estadio último -último, entiéndase, para nuestros intereses- lo representaría RM688, donde ha desaparecido ya también el último de los romances sin glosar y uno de los villancicos.

Así, creo que Melgar se basó para RM686 (o para un estadio anterior de RM686) en un pliego intermedio entre estos dos últimos estadios, es decir, un pliego que aún contenía el villancico Dama cogida en tu hato ${ }_{10}^{18}$ pero donde ya se había prescindido del romance de La bella malmaridada sin glosar, lo que explica que en RM686 se titule "Glosa de Quesada sobre el romance de la bella malmaridada”, información - la autoría de Quesada- que según acabamos de ver se ha perdido ya en RM688. O más concretamente: de ahí tomaría Melgar Quando amor en mi ponia, Viendo que mi pensamiento y el villancico, pues no olvidemos que RM686 comienza con otras dos composiciones.

\section{So los más altos cipreses y una hoja suelta de Melchor de Llanes}

$\mathrm{E}_{\mathrm{n}}$ nefecto, las dos primeras composiciones de RM686 (y RM685), Pensé que por bien amarte y Perdonad bien de mi vida, al igual que la composición de Torres Naharro que cierra el pliego, So los más altos cipreses, no proceden de ninguno de los supuestos estadios de RM689/688. Sin embargo, antes de intentar precisar de dónde pudo tomar el impresor esas composiciones, es necesario atender brevemente a los modos de composición de estos pliegos. Creo que en el caso del pliego suelto poético puede hablarse, con las obvias precisiones correspondientes, de dos modelos fundamentales de transmisión, teniendo siempre en cuenta que la unidad fundamental de

I8. Parece evidente que la grosera errata que transformó el original Dame acogida en tu hato en la Dama cogida de los pliegos tuvo que tener lugar en algún momento temprano de la transmisión. 
esa transmisión no son los propios textos, sino el impreso. ${ }^{19}$ En primer lugar, tendríamos aquellos pliegos que -como lo sería el propio RM685 respecto de RM686, o RM688 respecto de su modelo anterior- tienen como objetivo editorial primario la reproducción de un modelo anterior. En segundo lugar, estarían aquellos pliegos cuyo objetivo editorial es la creación de un mensaje nuevo; un mensaje que, con todo, ha de entenderse a nivel supratextual, pues lo crea el conjunto de los textos y no cada uno de ellos por separado (Garvin 2007: 23). Un ejemplo muy claro de a qué me refiero al hablar de mensaje supratextual lo constituye un pliego burgalés, impreso por Felipe de Junta “ $c$. ${ }_{5} 56 \mathrm{O}-\mathrm{I} 565$ " (Fernández Valladares 2005: $\mathrm{n}^{\circ}{ }_{544)} .^{20}$ El pliego en cuestión incluye seis romances, en principio muy diferentes entre sí, ya que hay entre ellos romances de historia de España, bíblicos y de materia clásica: Por los campos de Jerez, Quien en mal punto se engendra, Los cielos andan revueltos, Por los bosques de Cartago, Quando murió el rey Saul, Israel mira tus montes, En la rueda de fortuna y Bien vengas mal si eres solo. Sin embargo, tras esa clasificación -y no olvidemos que, en el romancero, cualquier tipo de clasificación implica una interpretación ${ }^{21}-$ se esconde, como ha puesto de manifiesto Giuseppe Di Stefano, un conjunto unitario sobre el tema de caída de príncipes y reveses de fortuna:

...el tema se ejemplifica alternando troyanos con otros peninsulares y bíblicos: la profecía del asesinato de Pedro el cruel, el sueño de Hécuba que profetiza las desventuras acarreadas por Paris, las desgracias del postrer rey de Navarra, la caída de Troya [...], la muerte de Saúl y Jonatás en la batalla de Gelboé, el consiguiente lamento de David, el asesinato de Polidoro y, en fin, la muerte atroz de Policena. (2000: I77)

En este segundo caso, cuando lo que se pretende es crear un mensaje nuevo, las composiciones pueden imprimirse por primera vez - como debió de ocurrir, aunque no sepamos exactamente cómo, durante los primeros quince años del siglo - o, lo que tendrá validez para gran parte de los años siguientes, mediante la recombinación de composiciones que ya tienen tras de sí una transmisión más o menos larga.

Tanto si un pliego pretende reproducir un modelo anterior como si lo que se pretende es la creación de un mensaje novedoso frente a la transmisión que le precede, la edición de un pliego tiene siempre una vertiente material que condiciona el resultado final. En el primero de los casos, puede condicionar la precisión o exactitud con que se lleve a cabo la reproducción del modelo, como hemos visto que ocurría en RM689-RM688, donde la supresión de ciertas composiciones venía causada, al menos en gran parte, por la diferencia de tamaño de los tipos usados. En el segundo, del mismo modo, la conjunción del espacio disponible -la hoja de pape ${ }^{22}-$ y los

I9. Por ello "el modelo general que ofrece el pliego prevalece sobre el aspecto textual de cada una de las composiciones que lo componen. Es por tanto el conjunto semántico -y no únicamente el espacio tipográfico- lo que determina en primera instancia el aspecto del cuaderno. Lo que predomina suele ser la necesidad de reproducir el cuaderno, por encima del texto o los textos individuales", Garvin (20I4: 298).

20. RM68o [+68I] Existen dos ejemplares uno en la Biblioteca Nacional de Madrid y otro en la Biblioteca de Catalunya. Hay edición facsímil en García Noblejas (ı957-6г: 3, пз3) y Blecua (ı976: nº 28). En este caso, la creación de ese mensaje supratextual al que me refiero es independiente de la más que posible relación de este pliego con cuadernos anteriores impresos en el mismo taller.

2I. Un ejemplo evidente de a qué me refiero puede verse en el magnífico artículo de Beltran (20I7: 45-II4) sobre los modos en que ciertos romances en torno a Cartago - que hoy en cualquier clasificación se hallarían dentro de la materia clásica-se emplearon como propaganda política, poniéndose en claro paralelismo con la toma de Túnez (I535).

22. Téngase en cuenta al respecto que "En la hoja básica de impresión, el llamado 'papel de marca', el pliego por antonomasia, de unos $440 \times 320 \mathrm{~mm}$ aproximadamente [...] caben numerosas posibilidades, aunque siempre contreñidas por la extensión original del papel, que a lo largo de todos estos años se ampliaron en diferentes opciones y disposiciones tipográficas y editoriales" (Infantes 2006: 352). 
materiales utilizables puede condicionar tanto los textos que se eligen como el modo en que se combinan.

Detengámonos ahora por un momento en los textos que, según todo parece indicar, el pliego RM686 toma de un modelo sevillano. No cabe ninguna duda de que tanto Quando amor en mí ponía como Viendo que mi pensamiento y Dama cogida en tu hato-además de las composiciones que glosan los dos primeros- pertenecen a ese amplio conjunto de textos que algunas compilaciones, como por ejemplo el Libro de cincuenta romances, denominan "de amores" ${ }^{23}$ Estaba claro, por tanto, que las composiciones que se eligieran para completar el pliego habían de seguir la misma temática a fin de obtener un cuaderno unitario.

Esa sería, por tanto, la primera y primaria razón en que habría que buscar los motivos de la elección: las composiciones encajaban temáticamente, y esto es algo igualmente válido si se creyera que el proceso tuvo lugar a la inversa, es decir, que el impresor comenzó la búsqueda por otro lugar, como por ejemplo el romance de Torres Naharro. Ahora bien, de poco sirve que una obra determinada encaje temáticamente en el conjunto si a la hora de la composición tipográfica hay problemas para amoldarla. Y aquí es donde creo que hay que tener en cuenta ciertos aspectos materiales, que tal vez puedan ayudarnos, si no a identificar la fuente concreta, sí al menos el modo de transmisión de estas composiciones.

Comencemos por el romance que cierra el pliego, So los más altos cipreses. De los cuatro que aparecen en la Propalladia de Torres Naharro, el presente es el que goza de mayor difusión en pliegos, gracias en parte al par de ellos que nos ocupa, RM686-RM685, ya que además de en estos aparece en $\mathrm{RM}_{594}$, $\mathrm{RM}_{35^{2}}$, en uno que solamente conocemos por la mención de Colón, RM884, y en otro RM4I2, si bien en versión muy distinta.

No es posible determinar en qué momento el romance comienza una andadura separado de los otros tres. En el Cancionero de romances de Martín Nucio los cuatro textos se recogen en bloque, tal y como aparecen en la Propalladia, y los pliegos en donde también aparecen así - RM352, impreso por Juan de Junta c. I554 con tres de los romances y, especialmente, RM594, que lleva los cuatro $^{24}$ - parecen posteriores al temprano pliego de Melgar, RM686. Resulta tentador pensar que Melgar, si como hemos visto tomó una parte del pliego de un cuaderno sevillano de Cromberger, pudo tomar también de allí la composición de Torres Naharro; no en vano las primeras ediciones penínsulares de la Propalladia son sevillanas y del propio Cromberger, ${ }^{25}$ pero lo cierto es que no lo sabemos. RM4I2 es también impresión burgalesa del propio Melgar, y aunque el texto del romance que aparece allí glosado es muy diferente al de la Propalladia, quizá testifica una fama del romance entre glosadores que el editor quiso aprovechar ofreciendo el texto exento. Sea como sea, la longitud del romance -70 versos, frente a los 47 de Con temor del mar airado, los 6o de Hïa soy de un labrador o los 228 de Nueva voz acentos tristes - también hubo de tenerse en consideración a la hora de adoptar el romance. Junto con el villancico Dama cogida en tu hato, So los más altos cipreses ocupa todo el vuelto de la última hoja y el espacio inferior del recto, el equivalente a cinco versos más el titulillo. A diferencia de lo que ocurre en el resto del pliego, estas composiciones no van divididas en estrofas.

23. En este caso concreto no sabemos cuáles son exactamente los romances que componían ese elenco. Véase al respecto Garvin (20I5: 36-56). Hay reproducción facsímil en Rodríguez-Moñino (I962: I65-I69).

24. No disponemos de propuestas de datación fiables para este pliego. Reproducción facsímil en García Noblejas (I957-6r: 3, ІІ8).

25. Después de la edición napolitana de Pasqueto de Sallo, I5I7, apareció en Sevilla una en torno a I520 (Griffin I99I: n. 202), Martín Abad (2OOI: $n^{\circ}$ I468) y otra en I526, ya posterior por tanto a la supuesta fecha de impresión del pliego de Melgar (Griffin I99I: $\mathrm{n}^{\circ}$ 264). 
Pasemos ahora a los dos textos con que se inicia el pliego: Pensé que por bien amarte y Perdonad bien de mivida. Como ya hemos visto más arriba, se transmiten en los siguientes pliegos:

Pensé que por bien amarte: $\mathrm{RM}_{321}, \mathrm{RM}_{322}, \mathrm{RM}_{32}, \mathrm{RM}_{324} \cdot 5$.

Perdonad bien de mi vida: $\mathrm{RM}_{32} 3, \mathrm{RM}_{324.5}$.

Esta distribución puede resultar algo engañosa, ya que no resulta tan claro que la segunda composición no se encuentre también en RM32 у RM R $_{322}$. Se trata de dos pliegos que únicamente conocemos por las referencias a ellos que hace Hernando Colón en su Abecedarium (Askins/ Infantes I997: 335-336). En ambos, el autor que Colón registra en "Melchior de Llanes". RM32I llevaría unos "Dialogos de mi caballo y un machuelo", que únicamente conocemos por este pliego, y RM322, una "Glosa sobre algunas canciones"; y en ambos se registra también nuestra primera composición, Penséque por bien amarte, glosa recordemos, del romance Desamada siempre seas. Pero la presencia de desechas no tiene demasiado sentido si no van acompañadas del romance, pues no olvidemos que "suelen ser un condensado lírico, en unos pocos versos, del romance que clausuran” (Botta 20I2: 74), por lo que no resulta ni mucho menos descabellado pensar que también Perdonad bien de mi vida iría en esos impresos. Por su parte, $\mathrm{RM}_{32} 3$ y RM324.5, pese a ser muy posteriores, refuerzan precisamente esa suposición, ya que allí sí aparecen ambas composiciones, precisando en la segunda que es una "desecha suya”, en referencia a Llanes. ${ }^{26}$ En algún momento de la transmisión -y RM686 bien podría ser uno de los primeros testimonios de ello- estas dos composiciones hubieron de separarse de esos pliegos de autor que registra Colón. Tal y como aparecen en nuestro pliego, esas dos composiciones ocupan exactamente la primera hoja por ambas caras y es posible que ese fuera también el espacio que ocupaban en los testimonios anteriores a él. De hecho, incluso en el caso de que la glosa de Llanes fuera acompañada del romance exento, Desamada siempre seas tiene solamente i6 versos, lo que no es impedimento para suponer una única hoja.

A la hora de componer un pliego, aun cuando no se siguiera un modelo previo sino que se quisiera crear uno nuevo, el uso de este tipo de unidades 'pre-fabricadas' debió de suponer una práctica habitual, según podemos deducir, por ejemplo, del modo en que los pliegos bifolios -o las dos hojas de un pliego en cuarto- se utilizaban en la composición de pliegos en cuarto y de cuatro hojas (un análisis detallado de esos métodos en Garvin 2020). Y es de suponer que lo mismo ocurría con hojas sueltas.

Vayamos por un momento a ese RM323 que ya hemos mencionado. Se imprimió precisamente en el taller de Felipe de Junta entre I560 y I570 (Fernández Valladares 2005: n 577 ), y permite vislumbrar unas costumbres que, como veremos, podemos retrotraer sin problemas hasta los pliegos que nos ocupan. El pliego en cuestión, en cuarto y de cuatro hojas, se titula: "Romance de don Roldan, trata como el emperador: Carlo Magno le desterro de Frāncia porque boluio por la honra de su primo Reynaldos. Y vna glosa nueuamente hecha por Melchior de Llanes sobre el romāce que dize. Desamada siempre seas, y vn villancico. Impresso cō licēcia”. Contiene, por tanto, cuatro composiciones: las dos que nos ocupan, el romance Dáa era de Sant Jorge, y el villancico Que por más que me digays. Esto y la formulación del título podrían sugerir una distribución más o menos equilibrada de las composiciones y las páginas, pero el romance de don Roldán tiene 288 versos y

26. Del pliego de Felipe de Junta se conservan dos ejemplares; facsímiles en García Noblejas (I957-6r: I, nº 26) para el de la Biblioteca Nacional de España y en Blecua (I976: n⿳⺈ I8) para el de la Biblioteca de Catalunya (RM324). Para la fecha del pliego burgalés, Fernández Valladares (2005: $n^{\circ}$ 577). Facsímil del pliego granadino en García de Enterría (I975: $\mathrm{n}^{\circ} \mathrm{II}$ ). 
ocupa las tres primeras páginas, aunque no completas. De hecho, la disposición del pliego resulta algo extraña, por desacostumbrada. El título es de siete líneas que se estrechan progresivamente mientras descienden; el grabado - quizá uno de los más usados en el taller-va orlado por cuatro barras, lo que hace que en esa primera hoja quepan únicamente ocho versos por columna cuando no hubiera sido difícil encajar una veintena. Por el final, el vuelto de la cuarta hoja solo está lleno hasta la mitad, cerrándose con dos líneas "Impresso con licencia, en Burgos en casa de Phelippe de Junta”. Parece obvio que ciertas decisiones se tomaron para poder sacar un pliego de cuatro hojas. Lamentablemente, es poco lo que conocemos sobre la transmisión anterior del romance de don Roldán, solamente un testimonio y además no conservado, sino registrado por Colón, RM55, "Hieronimi Bernal. Romance de don Roldan”. Pero si realmente el pliego solo llevaba ese romance, lo más probable es que estuviéramos hablando de un bifolio, un bifolio que Felipe de Junta completaría con una hoja ya compuesta -y de la que por tanto sabía perfectamente el espacio que le permitiría- que ya circulaba por el taller desde hacía décadas. Y es que el villancico que sigue a las composiciones de Llanes, Que por más que me digays, es sin duda un añadido, pero no de Felipe de Junta, ya que lo conocemos como remate desde pliegos mucho más tempranos. Y así llegamos a nuestro segundo par de pliegos: $\mathrm{RM}_{408}$ y RM409.

\section{$4 \mathrm{De} \mathrm{RM}_{4} \mathrm{O8}$ a RM409, pasando por RM4IO}

$\mathrm{R}$ $\mathrm{M}_{408}$ y RM409 consituyen los dos extremos de una cadena de transmisión cuyo nexo de unión es RM4IO. Los tres son pliegos en cuarto, de cuatro hojas. El primero fue impreso en Sevilla por Jacobo Cromberger entre I5I6 y I520 (Griffin I99I: n. 2I8), mientras que RM4IO lo imprimió en Burgos Alonso de Melgar “ $c$. I525” y RM409 en esa misma ciudad por Juan de Junta “c.153O-35” (Fernández Valladares 2005: $\mathrm{n}^{\text {os }} \mathrm{I} 69$ y 288). ${ }^{27}$ Los tres pliegos, pues, forman una secuencia idéntica en sus participantes a la que acabamos de ver en los pliegos anteriores. Tipológicamente, sin embargo, son pliegos muy distintos a ellos, en especial el de Cromberger.

En efecto, se trata, algo poco común, de un pliego de una única composición: el "Romance nueuamente hecho por andres ortiz en que se tratan los amores de Floriseo: y de la reina de bohemia”, tal y como reza el título, es decir, Quien hubiesse tal ventura. En la portada aparecen únicamente, en la parte inferior y enmarcado en orlas tipográficas el título recién mencionado e, igualmente enmarcados, dos (¿tres?) ${ }^{28}$ grabados, es decir, que el texto del romance no comienza hasta el vuelto de la primera hoja. Visualmente, el pliego se halla por tanto más cerca -dejando de lado obviamente su extensión- de un libro o una historia que de los pliegos sueltos al uso. ${ }^{29}$

Esta presentación se comprende aún mejor cuando analizamos algo más de cerca el romance en cuestión. Compuesto por un tal Andrés Ortiz, ${ }^{30}$ el romance que nos ocupa "está basado en el libro

27. No disponemos aún de facsímil del primero (pero véase Fernández Valladares et. al, en prensa). Sí de RM409 (García Noblejas i957-6r: III, Io8) y de RM4Io (Menéndez Pidal ı96r: II, 62).

28. El Nuevo diccionario habla de "dos grabados: dos damas de las cuales una escribe sentada; tres caballeros uno de rodillas”, pero al lado de estos puede verse una torre o la parte alta de una torre que allí no se menciona.

29. Puede compararse, por ejemplo, con el Libro de cincuenta romances (Rodríguez-Moñino I962: I65), que pese a aparecer registrado en el Nuevo diccionario como un pliego poético, RM936, debe considerarse como un impreso de más extensión, de ahí el diseño de la portada.

30. Además de nuestra serie de pliegos, conocemos a este autor por otro cuaderno, $\mathrm{RM}_{4} \mathrm{O}$, impreso en la misma ciudad de Sevilla en el taller crombergeriano en torno a I525 (véase Griffin I99ı: n 257), con unas "Coplas nueuamente trobadas sobre la prision del rey de Francia". Curiosamente, el pliego indica que fueron "Fechas por Andres ortiz a intercession de Gonçalo martinez de castro.” Sobre estos autores y los pliegos con “destinatario declarado”, véase Di 
II de la novela de caballerías Floriseo que por otro nombre es llamado el cauallero del Desierto el que por su gran esfuerço y mucho saber alcanço a ser rey de Bohemia" (García de Enterría I986: IO5), si bien no romancea todo el libro, sino que solamente se versifican los capítulos XXXVII a LVII en un total de 434 versos. Dado que el Floriseo se terminó de imprimir en Valencia, en casa de Diego Gumiel el ro de mayo de I5I6, podemos suponer que este pliego fue el primero, o al menos uno de los primeros, que transmitieron el romance en cuestión. Con ello, se insertaría en aquellos que, según apuntaba arriba, pretenden crear un mensaje nuevo, lo que explicaría a la perfección esta presentación gráfica a la que he hecho referencia, tanto la portada como el espacio en blanco que queda al final del vuelto de la cuarta hoja.

$\mathrm{RM}_{4 \mathrm{IO}}$, por su parte, puede considerarse como una copia directa de $\mathrm{RM}_{4} \mathrm{O} 8$, pero se han operado algunos cambios interesantes sobre este modelo. Lo primero que se percibe a nivel visual es que el diseño de la portada es distinto al del pliego sevillano. Si allí la primera página prescindía de texto, ahora Melgar opta por componer un pliego más acorde con la estética común en este tipo de impresos, con el título, debajo de éste un grabado, y a continuación el texto. En RM4IO, al igual que sucedía con RM686, los tipos empleados por Melgar son “ $\mathrm{M}_{2}$ c.I6o G ( ${ }^{\mathrm{a}}$ línea del título y encabez. interiores" y "M6 (b) c.97 G (resto del título y texto" (Fernández Valladares 2005: 582). ${ }^{31}$ Así que podemos saber que la redistribución del texto -que ahora comienza inmediatamente debajo del grabado, ofreciendo 28 versos del romance, I4 en cada columna - no se debe a exigencias tipográficas. El grabado, a diferencia del de Cromberger, es de una sola pieza, pero semánticamente semejante: si en el de Sevilla vemos, en el taco de la izquierda, a dos damas - una de ellas sentada y escribiendo, la otra tras ella de pie- y en el de su derecha a tres caballeros, uno de ellos arrodillado y de frente a la dama que escribe -la escena de Melgar representa lo que parece el interior de una iglesia-, tanto el Nuevo diccionario como Fernández Valladares (2005: 582) creen que se trata de una boda y lo describen como tal -de modo que el conjunto resulta, al menos, semejante.

Otra diferencia importante es que el pliego burgalés añade al sevillano un villancico final. La consecuencia obvia de que el romance empiece ya en el recto de la primera hoja, más aún cuando en la caja de Melgar caben 33 versos por $3^{2}$ en la de Cromberger, es que en el vuelto de la cuarta el espacio se agranda, dejando un espacio en blanco que se rellena con ese villancico. Lo realmente interesante es que este villancico que se añade no es otro que Que por más que me digays, el villancico que, según hemos visto arriba, aún Felipe de Junta añadía a la hoja suelta de Melchor de Llanes. Volviendo por un momento al par anterior, aumenta la sospecha de que aquellas dos composiciones de Llanes funcionaran como una hoja con un uso tipográfico concreto. Con esto no quiero decir que ciertas composiciones solamente se usaran para rellenar espacios en blanco, por supuesto, pero es innegable que existía entre los impresores una aversión al espacio en blanco y también que el uso de ciertas composiciones para cerrar esos huecos, como puede verse en el caso de este villancico, es recurrente.

Pero por lo demás, insisto, el objetivo que perseguía Melgar al reproducir este pliego de Cromberger es muy distinto a lo que buscaba cuando tomó una parte de un pliego y la combinó con otro, como veíamos arriba. El texto se mantiene básicamente igual que el sevillano si salvamos algunas (no pocas, pero poco significantes) variantes: ${ }^{32}$

Stefano (2OI4: 2II-224).

3I. Se anota, además, que "La presencia del tipo M6(b), que corresponde a una caja tipográfica adulterada, hace aconsejable no adelantar la datación de este pliego con anterioridad al año I523” (2005: 582). Podemos partir por tanto de la base que RM4IO y RM686 son básicamente paralelos.

32. Hay edición del romance en Guijarro Ceballos (I999: 3I3-334), quien, sin embargo, no pudo consultar el pliego

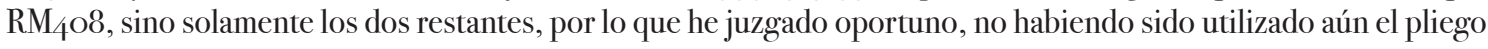
parisino en los estudios sobre este romance, listar esas variantes. 
3 como vuo floriseo $\mathrm{RM}_{4} \mathrm{O} 8$ como ovo floriseo $\mathrm{RM}_{4} \mathrm{IO}$

9 essa linda noble reina $\mathrm{RM}_{4} \mathrm{O} 8$ esta linda noble reina $\mathrm{RM}_{4} \mathrm{IO}$

I7 que desdel dia que yo os vi $\mathrm{RM}_{4} \mathrm{O} 8$ que desdel dia que yo os vide $\mathrm{RM}_{4} \mathrm{IO}$

39 yo estoy presto de hazerlo $\mathrm{RM}_{4} \mathrm{O} 8$ yo estoy presto para hazerlo $\mathrm{RM}_{4} \mathrm{IO}$

46 empeçan de retoçar $\mathrm{RM}_{4} \mathrm{O} 8$ empieçan de retoçar $\mathrm{RM}_{4} \mathrm{IO}$

53 a ellos parescian mal $\mathrm{RM}_{4} \mathrm{O} 8$ a ellos parecia mal $\mathrm{RM}_{4} \mathrm{OI}$

57 dandoles muy grande prissa $\mathrm{RM}_{4} \mathrm{O} 8$ dandoles muy grande priessa $\mathrm{RM}_{4} \mathrm{IO}$

64 della despedido se han $\mathrm{RM}_{4} \mathrm{O} 8$ della despedido se ha $\mathrm{RM}_{4} \mathrm{IO}$

7 $\mathrm{O}$ O mi señor floriseo R408 A mi señor floriseo RM4IO

8o ya empeça de nauegar RM408 ya empieça de nauegar RM4IO

8I y andado por sus jornadas RM408 y andando por sus jornadas RM4IO

9I andado por sus jornadas $\mathrm{RM}_{4} \mathrm{O} 8$ andando por sus jornadas $\mathrm{RM}_{4} \mathrm{IO}$

94 a reçebir se lo val $\mathrm{RM}_{4} \mathrm{O} 8$ a recebir se lo van $\mathrm{RM}_{4} \mathrm{IO}$

IO2 riberas la mar se va $\mathrm{RM}_{4} \mathrm{O} 8$ riberas del mar se va $\mathrm{RM}_{4} \mathrm{IO}$

I26 el suelo fuera saltar $\mathrm{RM}_{4} \mathrm{O} 8$ el suelo fuera a saltar $\mathrm{RM}_{4} \mathrm{IO}$

I28 y empiença assi de hablar RM408 y empieça assi de hablar RM4IO

I4O pues que sois de tal bondd $\mathrm{RM}_{4} \mathrm{O} 8$ pues que sois de tal bondad $\mathrm{RM}_{4} \mathrm{IO}$

I49 yos llevara con plazer RM408 yos llevare con plazer RM4IO

I77 a todos los que la oian $\mathrm{RM}_{4} \mathrm{O} 8$ a todos los que lo oian $\mathrm{RM}_{4} \mathrm{IO}$

208 hasta quel sol fu arrayado RM408 hasta quel sol fue rayado RM4IO

2II y tornando a sus criados $\mathrm{RM}_{4} \mathrm{O} 8 \mathrm{E}$ tornando a sus criados $\mathrm{RM}_{4} \mathrm{IO}$

$2 \mathrm{I} 2$ desque vuieron despertado $\mathrm{RM}_{408} 8$ desque uvieron despertado $\mathrm{RM}_{4} \mathrm{IO}$

2I8 de que aurades gran quebranto RM408 de que abreis gran quebranto RM4IO

23I y con muy grandes sospiros $\mathrm{RM}_{4} \mathrm{O} 8$ e con muy grandes sospiros RM4 $\mathrm{R}_{4}$

${ }_{235} \mathrm{O}$ fortuana desdichada $\mathrm{RM}_{4} \mathrm{O} 8 \mathrm{O}$ fortuna desdichada $\mathrm{RM}_{4} \mathrm{IO}$

239 su donzella peromencia $\mathrm{RM}_{4} \mathrm{O} 8$ su donzella piromencia $\mathrm{RM}_{4} \mathrm{IO}$

246 y ellos estando en aquesto $\mathrm{RM}_{408}$ y ellas estando en aquesto $\mathrm{RM}_{4} \mathrm{IO}$

247 nueuas llegado le han $\mathrm{RM}_{408}$ nueuas llegado les han $\mathrm{RM}_{4} \mathrm{IO}$

26r una dueña piromancia $\mathrm{RM}_{408}$ una dueña perimencia RM4IO

269 y con este buen eoncierto RM408 y con este buen concierto RM4IO

277 salvo que tiene su esforço $\mathrm{RM}_{4} \mathrm{O} 8$ salvo que tiene su esfuerço $\mathrm{RM}_{4} \mathrm{IO}$

324 que no habia de el gozar RM408 que no habia del gozar RM4IO

$34 \mathrm{O}$ en su cuerpo e menear RM408 en su cuerpo y menear RM4IO

350 el duque empeço a hablar RM408 el duque empieça a hablar RM4IO

365 Floriseo no le oya RM408 Floriseo no lo oia RM4IO

376 a Perineos sin dubdar $\mathrm{RM}_{4} \mathrm{O} 8$ a Perineos sin dudar RM4IO

396 un caballero vido asomar $\mathrm{RM}_{4} \mathrm{O} 8$ un caballero vio assomar RM4IO

403 no me lo qneray negar RM408 qno me lo querays negar RM4IO

$4 \mathrm{I} 8$ le vencio e quiso matar $\mathrm{RM}_{4} \mathrm{O} 8$ le vencio y quiso matar RM4IO

422 en el palacio fecho se han $\mathrm{RM}_{40} 8$ en el palacio hecho se han $\mathrm{RM}_{4} \mathrm{IO}$

423 y muy mas las sentia $\mathrm{RM}_{408}$ si muy mas las sentia RM4IO

424 essa reyna con su amar $\mathrm{RM}_{408}$ [este verso aparece dos veces] RM4IO

Magnificat CLM 8, 2021, I65-184. ISSN 2386-8295 
$4_{26}$ por el mas asolazar $\mathrm{RM}_{40} 8$ por el mas consolar RM4IO

433 y a vosotros los letores $\mathrm{RM}_{4} \mathrm{O} 8 \mathrm{y}$ a vosotros los lectores $\mathrm{RM}_{4 \mathrm{IO}}$

Como puede observarse, el pliego de Melgar contiene algunos errores, pero son casi siempre o bien errores de lectura -por ejemplo, consolar en lugar de asolazar en el v. 426- o malas lecturas ocasionadas por particularidades del modelo.

Fijémonos, por tomar un ejemplo, en lo que sucede con el verso 423, que RM4Io lee simuy mas, en lugar del y muy mas del modelo. ¿Cómo puede explicarse? El verso 42I es y muy grandes alegrías, mientras que el 423 es y muy mas las sentía. Esto en principio no debería ser problemático; pero en los tipos empleados por Cromberger, alternan dos para la $y$, uno más alargado $(y)$ y otro muy cercano al signo tironiano; y esos dos tipos se emplean en estos dos versos, teniendo el primero (42I) la y alargada y el otro (423, casi contiguo) el signo semejante al tironiano, lo cual refuerza aún más la sensación de que sean letras distintas. En ningún caso nos las habemos con innovaciones, sino con una tipología del error que encuentra su explicación en las operaciones de composición. Así ocurre, por ejemplo, con el verso 424, que como indicábamos, se repite en RM4IO. La explicación es tipográfica: la primera aparición del verso la encontramos al final del recto de la cuarta hoja y la segunda es el primer verso del vuelto de esa misma hoja. Si contemplamos ahora la imposición típica de un pliego en cuarto de cuatro hojas, veremos que mientras la una se encuentra en la cara externa del pliego, la otra se encuentra en la interna, de modo que lo que sucedió fue que durante la cuenta del original se hizo una marca de cambio de plana que los operarios interpretaron como último verso de una cara y, al mismo tiempo, como primer verso de la siguiente. ${ }^{33}$

Dejando de lado estos errores, lo cierto es que pese a ser una copia de RM408, RM4IO ofrece en muchos casos un mejor texto que el pliego de Cromberger, lo que lleva a plantearnos hasta qué punto no deja de ser un prejuicio considerar que la primera edición de un pliego ha de suponerse textualmente más cuidada que sus sucesoras. Tiene sus propias particularidades ortográficas, como la sustitución en algunos casos de $e$ por $y$, además de corregir en muchos casos erratas del pliego sevillano, algunas - bondd por bondad, v. I4O; fu arrayado por fue rayado, v. 208: fortuana por fortuna, v. 235 o eoncierto por concierto, v. 269- sin duda evidentes; pero en general, ofrece mejores lecciones. Melgar convierte por tanto el pliego sevillano en un pliego más al uso, asemejándolo visualmente al pliego-tipo que se perfila claramente ya por esas décadas, y añadiéndole un villancico que completa, tipográfica y semánticamente, el cuaderno.

Cuando Junta, por su parte, copia RM4IO, la voluntad de innovación es nula; lo que se busca es, única y exclusivamente, reproducir el modelo que ofrece el pliego de Melgar. De hecho, es necesario un análisis detallado para percibir las diferencias. El grabado utilizado es exactamente el mismo, pero los tipos son distintos: los empleados por Junta en RM409 son "MA c.I48 G ( $\mathrm{I}^{\mathrm{a}}$ línea del título y encabez. interior): M6(b) $98 \mathrm{G}$ (resto del título y texto)" (Fernández Valladares 2005: 732); quien compare el pliego con detalle puede ver, por ejemplo, que la Q del primer verso es distinta en ambos impresos. Hay, además, variantes ortotipográficas, como puede constatarse en las diferencias del título:

Romāce nueuamēte hecho por Andres ortiz en que se tratan los amores de floriseo: y de la reyna de bohemia Con un villancico. $\mathrm{RM}_{4} \mathrm{IO}$

33. Una buena representación gráfica de esta imposición podemos encontrarla en Gaskell (I972: 89). Véase también Garza (2000: 65-95). 
Romance nueuamente hecho por Andres Hortiz en que se tratan los amores de Floriseo: y de la Reyna de Bohemia con un Villancico. RM409

La fidelidad con que Junta sigue su modelo es tal, que incluso se reproduce ciegamente ese verso repetido que apuntábamos en $\mathrm{RM}_{4} \mathrm{IO}$. Sin duda alguna, el pliego de Junta busca ser una copia exacta de RM4IO, tan exacta como pueda serlo una copia en la época de la imprenta manual.

Obviamente las dos series de pliegos estudiadas no dejan de ser casos concretos en un universo que sabemos complejo e incompleto. Creo, sin embargo, que el estudio detallado de este tipo de piezas revela informaciones de importancia para que nuestra visión y comprensión de la transmisión de romances en pliegos sueltos quinientistas sea, si bien parcial, lo más acurada posible. 


\section{Obras citadas}

Askins, Arthur L.F.; Infantes, Víctor; Rodríguez-Moñino, Antonio. 1997. Nuevo diccionario bibliográfico de pliegos sueltos poéticos (siglo XVI) (Madrid: Editora Regional de Extremadura)

Askins, Arthur L.F.; Infantes, Víctor. 20I4. Suplemento al 'Nuevo diccionario bibliográfico de pliegos sueltos poéticos (siglo XVI)'de Antonio Rodríguez Moñino, ed. by Laura Puerto Moro (Vigo: Academia del Hispanismo) <https:// doi.org/IO.400o/criticon.I279>

Beltran, Vicenç. 2005. 'Los primeros pliegos poéticos: alta cultura / cultura popular', Revista de Literatura Medieval, I7: 7I-I2O <http://hdl.handle.net/IOOI7/5447 $>$

Beltran, Vicenç. 2005-2006. ,Del pliego de poesía (manuscrito) al pliego poético (impreso)', Incipit, 25-26: $2 \mathrm{I}-56$ <https://go.uv.es/giWIUvk $>$

Beltran, Vicenç. 20I6. El romancero: de la oralidad al canon (Kassel: Reichenberger)

Botta, Patrizia. 20I2. ,Desechas al pie de romances en el Cancionero de Castillo', in Estudios sobre el Cancionero General (Valencia, 1511): poesía, manuscrito e imprenta, ed. by Marta Haro et al., (València: Universitat de València), pp. 7I-95

Castillejo Benavente, Arcadio. 20I9. La imprenta en Sevilla en el siglo XVI (1521-160o) (Córdoba; Sevilla: Universidad de Córdoba; Universidad de Sevilla)

Di Stefano, Giuseppe. r99o. „Edición “crítica” del romancero antiguo: algunas consideraciones“, en Actas del congreso Cancionero-Romancero, UCLA 1984, ed. by Enrique Rodríguez-Cepeda (Madrid: Porrúa Turanzas), I: 29-46

Di Stefano, Giuseppe. 2000. ,El pliego suelto, del lenguaje a la página“, en Imprenta y crítica textual en el Siglo de Oro, ed. by Francisco Rico (Valladolid: Universidad de Valladolid), pp. I7II85

Di Stefano, Giuseppe. 20I4. ,Pliegos sueltos poéticos con destinatario declarado', Revista de Poética Medieval, 28: pp. 2II-224 <https://doi.org/IO.37536/RPM.20I4.28.0.53204>

Fernández Valladares, Mercedes. 2005. La imprenta en Burgos, 1501-160o (Madrid: Arco Libros)

Fernández Valladares, Mercedes. 2006. ,Indicios y evidencias para la asignación tipobibliográfica de los pliegos sueltos burgaleses del siglo XVI", in La literatura popular impresa en España y en la América colonial: formas y temas, géneros, funciones, difusión, historia y teoría, ed. by Pedro M. Cátedra and Eva Belén Carro Carbajal (Salamanca: SEMYR), pp. 437-475

Fernández Valladares, Mercedes. 20I2. ,Biblioiconografía y literatura popular impresa: la ilustración de los pliegos sueltos burgaleses (o de babuines y estampas celestinescas)", eHumanista, 2I: 87-I3I $<\underline{\text { https://go.uv.es/AcUhfP } 7}>$

Fernández Valladares, Mercedes; Puerto Moro, Laura; Mahiques Climent, Joan. (In press). Pliegos poéticos españoles del siglo хVI en bibliotecas de Francia (México: Frente de Afirmación Hispanista)

García de Enterría, M. Cruz. 1975. Pliegos poéticos españoles de la Biblioteca Universitaria de Cracovia (Madrid: Joyas Bibliográficas)

García Noblejas, José Antonio (ed.) (I957-I96I). Pliegos poéticos góticos de la Biblioteca Nacional de Madrid, 6 vols (Madrid: Joyas Bibliográficas) 
Garvin, Mario. 2007. Scripta Manent: hacia una edición crítica del romancero impreso (Siglo XVI), (Madrid-Frankfurt: Iberoamericana)

Garvin, Mario. 20I4. ,La lógica del pliego suelto: algunos apuntes sobre la materialidad en la transmisión poética', in La poesía en la imprenta antigua, ed. by Josep Lluís Martos (Alacant: Universitat d'Alacant), pp. 295-309

Garvin, Mario. 20I5. ,El Libro de cincuenta romances: historia editorial de un impreso perdido“, Zeitschrift für Romanische Philologie, I3I: 36-56 <https://doi.org/IO.I5I5/zrp-2OI5-OOO3>

Garvin, Mario. 20I9. ,Fuentes impresas del romancero: el caso de los pliegos poéticos sevillanos de la primera mitad del siglo XVI", in Pragmática y metodología para el estudio de la poesía medieval, ed. by Josep Lluís Martos and Natalia Mangas (Alacant: Universitat d'Alacant), pp. 235-252

Garvin, Mario. 2020. 'La condición bifolia: los impresos de dos hojas y la transmisión del pliego suelto poético', Revista de Poética Medieval, 34: 83-Io6 < $\underline{\text { https://doi.org/IO.37536/ }}$ $\underline{\text { RPM.2020.34.0.77378> }}$

Garza, Sonia. 2000. ,La cuenta del original', in Imprenta y crítica textual en el Siglo de Oro, ed. by Francisco Rico, Pablo Andrés and Sonia Garza (Valladolid: Universidad de Valladolid), pp. 65-95

Gaskell, Philip. 1972. A New Introduction to Bibliography (Oxford: Clarendon Press)

Griffin, Clive. 1991. Los Cromberger: historia de una imprenta española del siglo XVI en Sevilla y Mexico (Madrid: Cultura Hispánica)

Griffin, Clive. I993. ,Un curioso inventario de libros de I528“, in El libro antiguo español, I: Actas del primer coloquio internacional, Madrid 1986, ed. by Pedro M. Cátedra and M. L. López Vidriero (Salamanca: Universidad de Salamanca), pp. I89-224

Griffin, Clive. 1998. ,El inventario del almacén de libros del impresor Juan Cromberger, Sevilla I540', in El libro antiguo español, IV: Coleccionismo y bibliotecas (XV-XVIII), ed. by Pedro M Cátedra, M. López Vidriero and M.I. Hernández González (Salamanca: Universidad de Salamanca), pp. 257-273

Infantes, Víctor. 1988. „Los pliegos sueltos poéticos: constitución tipográfica y contenido literario“, in El libro antiguo español, I: Actas del primer coloquio internacional, Madrid 1986, ed. by Pedro M. Cátedra and M. L. López Vidriero (Salamanca: Universidad de Salamanca), pp. 237-248

Infantes, Víctor. 2006. „Historia mínima (y desde luego incompleta) de los impresos de una sola hoja, II: Los años áureos", in Edad de oro cantabrigense: actas del VII Congreso de la Asociación Internacional Siglo de Oro, Cambridge, 2005, ed. by Anthony Close (Cambridge: AISO), pp. 35 ${ }^{\text {I- }}$ 356 <https://go.uv.es/3oBvPXI $>$

Menéndez Pidal, Ramón. I96r. Pliegos poéticos españoles en la Universidad de Praga (Madrid: Joyas Bibliográficas)

Moll, Jaime. 2003. ,El taller de la imprenta“, in Historia de la edición y de la lectura en España 1472-1914, ed. by Víctor Infantes, Francois Lopez and Jean-François Botrel, (Madrid: Fundación Germán Sánchez Ruipérez), pp. 3-38

Norton, F.; Wilson, E.M. 1969. Two Spanish Verse Chap-Books: Romance de Amadis (c. 1515-19), Juyzio hallado y trabado (c. 1510) (Cambridge: Cambridge University Press)

Norton, Frederick. 1978. A Descriptive Catalogue of Printing in Spain, 1501-1520 (Cambridge: Cambridge University Press) 


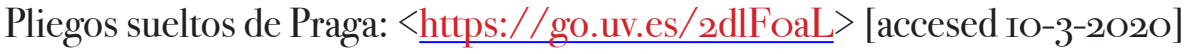

Rodríguez Moñino, Antonio. 1976. Los pliegos poéticos de la Biblioteca Colombina (siglo XVI) (Berkeley: University of California Press)

Rodríguez-Moñino, Antonio. 1962. Los pliegos poéticos de la colección del Marqués de Morbecq, siglo XVI: edición en facsimil precedida por un estudio bibliográfico (Madrid: Estudios Bibliográficos)

Rodríguez-Moñino, Antonio. I97o. Diccionario bibliográfico de pliegos sueltos poéticos (Madrid: Castalia)

Wilson-Lee, Edward. 2org. Memorial de los libros naufragados: Hernando Colón y la búsqueda de una biblioteca universal (Madrid: Ariel) 